\title{
Preface: Intentionality and Reality
}

TO WHAT KIND of worry should a statement of realism be a response? Probably, in the first place, a sense of having lost contact with the world.

The great accomplishment of the twentieth century was the discovery of the incredible richness and variety of the symbolic realm, of how many signs and codes articulate our relation to reality. Perhaps a downside of this huge step forward is the impression that all those signs and their codes merely separate us from reality by forming a kind of screen between it and ourselves. As though reality were concealed behind meaning and consequently-since meaning proves to be very complex-infinitely far from us.

Perhaps then realism should be understood as the affirmation that there really is something beyond the veil of meaning. What, however, should 'really' mean here? It is hard to make sense of what it could mean apart from signalling a kind of 'transcendence': there really is something that cannot be reduced to an idol of meaning, there is something that exists beyond meaning.

It is very tempting to translate this idea of the transcendence of reality to meaning into some kind of essential, metaphysical meaninglessness. As if reality needed to be meaningless in order to be truly beyond meaning.

This characterization, however, is equivocal. It can mean that reality is a category to which it makes no sense to apply the concept of meaning; reality is just what it is-that is its definition-and 
thus does not have meaning itself. However, on a substantial understanding of 'meaninglessness,' it does not make sense to call reality 'meaningless.' For on that understanding, to call something 'meaningless' presupposes the possibility of its being 'meaningful,' in which case the notion of meaning applies to reality after all.

One powerful trend in contemporary philosophy has understood the meaninglessness of reality in the second sense, that is, not as a categorical difference but as something more substantial; as if meaninglessness were a positive property of reality. ${ }^{1}$ Jean-Paul Sartre, for example, having avoided the pitfall of conceiving reality as an 'obstacle'-which is still a way of interpreting it from a perspective which grants it some definite 'meaning' - insists on reality's indifference to meaning, as though it were a kind of stupidity or, put differently, an essential, and apparently agonizing meaninglessness. Reality, however, is not 'stupid': it just is what it is. Why should we feel a lack of meaning here? Is this not a way of once more mistakenly expecting something reality cannot give, not because of any kind of positive metaphysical impossibility, but simply because it is a category mistake to think that reality could possess meaning?

It seems, however, that a large swathe of contemporary philosophy is convinced of having lost contact with reality to such an extent that it feels the need to discover some kind of break in meaning, in order that it might recover the feeling of making contact with it again. An interesting example of this attitude can be found in the Italian philosopher Maurizio Ferraris's conversion to realism a few years ago, which he describes in his book The External World. ${ }^{2}$ Ferraris explains cum grano salis that he was, so to speak, struck by a reality beyond every construction or representation when he experienced an earthquake in his hotel room whilst staying in Mexico City. Of course, the anecdote speaks for itself precisely because that

I. One can find traces of this view at the core of 'speculative realism' as it has been framed by Meillassoux (2010).

2. Ferraris 200I. 
particular instance of reality may well be beyond the reach of our familiar speech. The earthquake questions that very 'grounding soil' of evidence that Edmund Husserl highlighted as an essential basis for meaning. From that point of view, the image of the earthquake is powerful.

Now, it is necessary to ask how it comes to pass that a philosopher needs anything like an earthquake in order to get real. Reality is everywhere, not just in brutal breaks in or from meaning-not only in what we cannot make sense of. Why should reality necessarily take on the form of a catastrophe? This kind of view can correctly be described as a subtle form of negative anthropomorphism.

In fact, I do not think Ferraris himself endorses such a 'catastrophic view.' He believes, like everyone else, that the rooms we are all familiar with are just as real as an earthquake. What is interesting, however, is that he feels compelled to use that kind of example in order to make his point about the 'non-cancellability' (inemendabilita) of reality. Reality is, in some sense, 'stronger' than meaning - and at any rate independent of it. In this kind of argument we always find the same basic idea of reality's 'transcendence,' as if what primarily characterizes reality in its irreducibility is that it is beyond the sphere of meaning.

Now, from time to time making sense of reality presents a difficult challenge. That this is possible is surely an essential part of what we call 'reality.' It is an aspect of the concept of reality. But it would be a mistake to think that it forms the core of the conceptthat it is, so to speak, reality's trademark.

This is firstly because, as we have mentioned, 'failing to correspond to human meaning' is a characterization of reality that remains within meaning and so, to some extent, makes the concept of reality dependent on meaning — at least in a negative way. Secondly, it seems important that when circumstances are favourable, meaning is able to capture reality-just as it is true that we can find no meaning for it when circumstances are unfavourable. Of course, the simple fact that we can succeed or fail in meaning something is 
already proof that meaning something occurs on solid ground. Both success and failure are only possible within reality.

Through this remark we have already switched from a point of view according to which reality is, or fails to be, in front of what we mean, to a point of view according to which it is, so to speak, all around it-its very element. I will return to this point at the end. However, let us first explore in greater depth the fact that if we succeed in meaning something, then-when what we mean is realour meaning adequately captures the thing in its reality. Yet depending on the perspective we adopt, this assertion may or may not turn out to be tautological.

According to one perspective it is tautological, since-on a fairly central use of the word 'meaning' — nothing need be added to meaning in order for it to reach reality: this is just what meaning does. From a different perspective, saying that meaning-when successfulcaptures reality as such, is not to have said nothing. It is to insist on the fact that the 'the thing itself' is met within meaning. This presupposes that such a thing can be thought of as 'being itself.' Indeed, this is what we call its 'reality.'

Now, what does it mean to say 'the thing's being itself'? This is not an issue of identity. For there is no identity without an identification. The same thing can be identified in very different ways. This is an important aspect of meaning: our being able to identify what is meant as such and such. Now, for something to 'be itself' is just for it to be the very thing it is. 'Being itself' is not something that the thing can be identified as, except in very specific situations. This is what we can call the 'ipseity' or 'selfhood' of the thing. We can call real everything that has an ipseity, that is to say a being of its own. Or in other words, everything real is said to be in a sense of 'being' that is independent of being meant.

Now, in a lot of cases, meaning is concerned precisely with this ipseity-with 'things being themselves' - and it captures this ipseity wherever it succeeds. This is because the thing's being this or that is just a guise of its being itself. However, it would be a mistake to 
understand a thing's being what it is as a borderline case of its being this or that. In fact it would be a category mistake: 'being itself' is not-except in metaphysics-a way it makes sense to characterize something as being. Nevertheless, very often it is in view of the thing's 'being itself' that we say it is this or that. As such, meaning concerns reality.

We can say that what we mean is real whenever it is in an additional sense than that of simply being meant-although what is meant in this additional sense may well be the same as that which is meant. In other words, one of meaning's powers consists in being able to refer to the way things are in a sense other than the one found in the mere notion of being meant.

There is, therefore, no need to look for a realm transcendent to meaning in order to establish reality-as if reality were the sort of thing that could be established. It is enough to look at meaning: its claims and accomplishments. If we examine meaning we shall everywhere find reality as precisely that upon which meaning articulates a perspective. It makes no sense to say that reality as such is 'beyond' meaning: it is just what meaning, at least in many cases, is concerned with. Reality should not be confused with what meaning makes of it. That is just a category mistake. However, reality is not 'beyond' meaning either. Sometimes it is that for which we cannot find a meaning — we just do not know what to make of it—but sometimes it is exactly what is meant. Yet even in the latter case, reality is not simply identical to the meaning that captures it. Nor is it for that reason any less real than when we can find no meaning for it.

As a matter of fact, the false problem of reality's 'transcendent' nature results from the mistaken perspective according to which reality can be or fail to be in front of our meaning. On such a view, since it is not always clear whether meaning has a 'counterpart'and because reality appears to play the role of such a counterpart-it is necessary sometimes for experienced reality to exceed whatever meaning we can find for it, as this excess is thought to provide proof of the existence of the reality that lies in front of meaning. 
Now, the fact that, sometimes, we find ourselves lacking meaning for some things does not prove that there is any intrinsic transcendence of those things to meaning in general, but only that thus far we have not been able to find a meaning for them. This is a point about meaning rather than the things themselves. Conversely, the fact that sometimes we may actually doubt whether there really is anything 'in front' of meaning has to do with meaning as such: it just indicates that in those cases, we were not able to find a meaning that refers and thus in some sense any meaning at all (on a fairly central use of the word 'meaning' at least). It is not that, in front of meaning, there is something that is really lacking. The defect is in our meaning.

Thus, realism about meaning simply requires us to forswear this kind of 'frontal' perspective. What is much more at issue is our capacity to develop a perspective on reality-which is at least one dimension or usage of the concept of meaning. Now, this capacity is something that is only exercised within reality. Meaning is something that can neither refer to reality successfully_nor fail in doing so-'from outside.' Neither success nor failure are possible outside the realm of reality. Meaning itself, as a mere take on something, is nothing real. However, meaning as such-especially since in many cases it concerns reality-always presupposes reality as its basis and the space of its conditions. For we cannot mean anything without meaning it from somewhere-and, so long as we can standardize this somewhere and characterize those conditions, they always remain real. When analysing any particular meaning, one should always pay as much attention to its presuppositions regarding what is real-that is to say, the reality on which it rests and that makes it possible as the particular meaning it is-as to what it claims to be real. Reality is as much upstream from meaning as it is downstream of it.

That is a point about context. Once again: context is not so much an external constraint on meaning-as if reality, so to speak, struck meaning from the outside-as it is the manifestation of meaning being effectively rooted in reality, as well as something that contributes to 
the constitution of meaning itself. If meaning does not have to 'make contact' with reality, that is because it is already active as a genuine normative 'move' within the space of reality. In other words, meaning is a concrete way within a determinate situational framework (which can be more or less abstract), of having a take on some part of reality. One can mean something to be thus and so, only if, in the background, some things are what they are. Things being 'what they are' can in turn be characterized, in other takings, as being this or that. But it is important that in one take on reality, the background remains blind, remains mere 'reality.'

So, there is something decidedly misleading in a common way of formulating the realist position, as if the problem was how one can assert the presence of some sort of counterpart for our various meanings, one that might be missing. In fact the real task is to situate these meanings within reality whilst making sense of the normative framework they set up for this 'reality.' This way it is possible to see that, wherever meanings are effective, they just are contact with reality.

Once the real conditions and purport of meaning are understood, the epochal worry about the meaning's ability to make contact with reality turns out to be a worry about our meaning something much more than about whether or not things exist 'in front of' meaning. The problem should be reformulated this way: When are we really meaning something? Which is also to ask: When are we really involved in our meaning, instead of remaining outside of it? The doubt about our ability to mean anything real is, at bottom, a doubt about our capacity to mean anything at all. For it is an intrinsic question regarding meaning why one should ever be able to mean anything.

Chapter I was first published as "Why Should Inexistent Objects Be a Problem?" in Intentionality. Historical and Systematic Perspectives, edited by Alessandro Salice and published by Philosophia Verlag in 2OI2. Chapter 2 first appeared in print as "The Internal and 
the External in Knowledge," in Rethinking Epistemology, vol.I, edited by Günter Abel and James Conant Berlin and published by de Gruyter in 20I2. Chapter 3 was published as "First Person is Not Just a Perspective: Thought, Reality and the Limits of Interpretation" in Consciousness and Subjectivity, edited by Sofia Miguens and Gerhard Preyer and published by Ontos Verlag in 20I2. Chapter 9 appeared as "Making Ontology Sensitive," Continental Philosophy Review, vol. 45, no. 3, September 20I2, p. 4II-424. Chapter Io was first published as "Realism Without Entities" in Idealism, Relativism, and Realism, edited by Dominik Finkelde and Paul Livingston and published by De Gruyter in 2020. The original texts appear here with minor edits.

I would like to thank Sandra Laugier, whose proximity made me who I am philosophically; James Conant, who taught me everything about philosophizing in the English-speaking world and who thus opened me up to a new way of practising philosophy, and Charles Travis, whose influence reshaped every problem for me, helping me out of so many pieces of philosophical nonsense. Thanks to Rory O'Connell, as well, who helped me revise my English text. 
Toward a Contextual Realism 
